Research Article

\title{
Feature Design Assessment of the Ship Fire Alarm System
}

\author{
Haoyang Han, Jundong Zhang $\mathbb{D}$, and Ruizheng Jiang \\ College of Marine Engineering, Dalian Maritime University, Dalian 116026, China \\ Correspondence should be addressed to Jundong Zhang; 20140963@stu.nun.edu.cn
}

Received 3 June 2021; Revised 4 July 2021; Accepted 10 July 2021; Published 23 July 2021

Academic Editor: Muhammad Usman

Copyright (C) 2021 Haoyang Han et al. This is an open access article distributed under the Creative Commons Attribution License, which permits unrestricted use, distribution, and reproduction in any medium, provided the original work is properly cited.

Damages and misfortunes caused by fire on ships have recently accelerated the creation of new approaches, development, and building the security and unchanging quality of the fire detection framework. Simultaneously, with the growing interest in better early fire detection and prevention, numerous frameworks are being created for the detection of progress, with control calculations having the task of carefully preparing and identifying true/false signals from fire or flames or the true alarm from false alarms. By utilizing the assistance provided by innovation, transport owners are more likely to service groups and fleets of ships and reduce potential fire accident costs. This article provides an overview of recent methodologies and technology for early detection of ship fires, as well as an enhanced approach for evaluating the Human-Machine-Interface (HMI) function of an alarming ship using a machine operating simulator called DMS-2017B. The DMS-2017B machinery operation simulator can unify the noise environment to avoid the influence of environmental differences on cabin experimental results. Compared to conventional Binomial Testing, a ship simulator coupled with the theory of affordance that provides a more realistic and operable way to assess the feature design of ship fire alarm and the threshold of some influence factors can also be used. According to the quantitative analysis of experimental results based on the ordered logit model, the function of the ship fire alarm would be improved significantly by adding recorded broadcasting and replacing static symbols with flashing symbols. Increasing sound pressure is also an effective way of doing this, but an auditory threshold is present. Above $75 \mathrm{~dB}$, this effect will fade down, along with noise pollution. However, the effect difference between continuous alarm and square wave pulse alarm is negligible. The conclusion can provide some guidance for the design of a ship fire alarm. An appropriate design is expected to facilitate the efficiency of handling accidents and guiding evacuation.

\section{Introduction}

The primary goal of a fire alarm system is to offer an advance indication of a fire so that people can be removed and prompt action can be taken to minimize or eliminate the fire's effect. For this purpose, detectors or a manual call point can be used to set off an alarm. There are dozens of ship alarms and call signals. These alarms can be divided into four classes by priority level: emergency alarm, alarm, warning, and caution $[1,2]$. All alarms are required to indicate by audio and visual means to keep the visual alarm unaffected when the audible alarm is interrupted by a notice and make sure that all passengers and crew members can receive alarm information in an unobstructed manner [3-5]. Accidents and casualties cannot be avoided from happening, even if marine vehicles are installed with the warning system that is exactly specified by IMO [6, 7]. Over 500 major marine accidents happened after 1980; as of 2010, death tolls hit 1,824 [8-10]. On 16 April 2014, MV SEWOL heeled at turning, resulting in 296 deaths and 8 persons reported missing [11]. It was alarmed when this accident occurred, but high school students as a part of passengers remained still and failed to evacuate right away, resulting in 250 deaths [12]. As indicated by the United States fire administration [13], the assessment of yearly private structure fire deaths in the United States is somewhere in the range of 2385 and 3050 from 2003 to 2012. The investigation of [14] shows that one out of four (1/4) lasting inhabitants (24.2\%) were sleeping at the hour of start, while in flames that brought about fatalities, four out of five lethally harmed (80.5\%) were snoozing. The US fire administration reports that over $88 \%$ of the homes in the United States have at any rate 1 fire alert 
introduced. However, $60 \%$ of the private fire deaths happen in homes without an operational caution analysis of information from the United States fire organization's national fire incident reporting system (NFIRS) and the NFPA's fire office study showed that from 2003 to 2006, no fire alerts were available in $31 \%$ of revealed home flames and $40 \%$ of home fire deaths [15]. It matters that alarm can be understood and trusted. The feature design of ship alarm has been preferably discussed in present works.

Extensive works related to the design of fire alarm systems have revealed that the design of alarm features often decides whether information can be noticed and understood. For instance, the volume test of fire alarm found that $20 \%$ of persons are unable to properly respond to $60 \mathrm{~dB}$ fire alarm due to background noise, signal meaningfulness, signal frequency, hearing loss, time of night, and stage of sleep. Instead, $90 \mathrm{~dB}$ fire alarm leads to better results [16-18]. Wireless fire alarm systems should fulfill current criteria, be simple to install, quick, and inexpensive, and avoid damaging the surface of the structure by causing the slightest alterations in the features of easy adaptation [19]. Another work suggested that a fire alarm should be added with the broadcast so that the alarm information can be further understood and recognized [20]. Another associated work revealed that dynamic signs would be more visible than static signs, which means an increase of visibility level from $38 \%$ to $77 \%$ [21].

A simple comparative experiment is often carried out to compare the difference of a single feature of alarm. If more features need to be considered, statistical algorithms are generally used to avoid mistakes and estimation errors [22]. Binomial testing is a traditional method to assess the effect of the feature design of emergency evacuation appliances. This paper is intended to observe the feature design effect of ship fire alarms and identify which feature may be modified to make persons better aware of alarms. Ship simulator was used to acquire experimental data and filter errors. Results were analyzed using the ordered logit model and then compared with the findings of real experiments and binomial testing. The reliability, strengths, and weaknesses of the proposed procedure were validated. The main contributions of the proposed study are listed in the following:

(i) Numerous human deaths occur in ships due to fire. The proposed scheme helps to save important human lives by designing an intelligent ship alarm system.

(ii) This paper offers an approach to building a ship fire alarm by using the DMS-2017B machinery operation simulator.

(iii) The proposed ship simulator is coupled with the theory of affordance that provides a more realistic and operable way to assess the feature design of the ship fire alarm system.

(iv) In addition, both continuous alarms and pulse alarms are incorporated as a part of the auditory feature design of ship fire alarms.

(v) Finally, various simulation experiments such as the Cabin experiment and Binomial testing are conducted to verify the advantage of the method in the ship fire alarm system. The results of three experiments indicated that the sound pressure increased from $60 \mathrm{~dB}$ to $75 \mathrm{~dB}$ and replacing static signs with dynamic signs can significantly enhance the function of the fire alarm under the noise environment in a ship's cabin.

The rest of the paper is organized as follows. In Section 2, we discuss the materials and methods for the proposed approach. In Section 3, we explain our experimental works. A short discussion of the proposed scheme is presented in Section 4 and the conclusion is provided in Section 5.

\section{Materials and Methods}

2.1. Fire Alarm System. The Fire Alarm System is intended to notify us of an emergency so that we can take appropriate measures to protect ourselves, our employees, and the general public. Fire alarms are discovered in ships, offices, factories, and public buildings; they are a part of our daily routine but are easily ignored until an emergency occurs, at which point they may save our lives. Whatever method of identification is used, if the sensor is activated, sounders will sound to alert people in the area that there may be a fire and to advise them to evacuate. The fire alarm system may include a remote signal system that alerts the fire department via a control center. The Fire Alarm Control Panel is the "brain" of the fire detector system. It serves as the central hub for all detector signals and displays a status indicator to users. The detection systems are at the heart of a fire alarm system, ranging from complex, intelligent fire alarms to simple manually operated break glass units. There are many different types, but we can categorize them into five types [15] as in Figure 1.

2.1.1. Heat Detector. Heat detectors can operate on a specified temperature basis, triggering an alarm if the temperature exceeds a preset value or on the rate of variations in climate. Heat detectors work similarly to electrical fuses in that they encompass a eutectic alloy that is heatsensitive; if a certain threshold is achieved, the alloy transforms from a solid to a liquid, triggering the alarm.

2.1.2. Smoke Detectors. This kind of detectors can be classified into three types [17]:

(i) Ionization. Ionization, a smoke alarm typically has two tubes. The first one is used to compensate for changes in temperature, humidity, or pressure. The second chamber consists of a radiation material, typically an alpha particle, which ionized particles the air passing through the chamber, which includes 2 electrodes and a current flowing among both them. The flow of current tends to decrease when smoke enters the chamber. This decrease in current flow is used to set off an alarm.

(ii) Light Scattering. The Tyndall effect is used in the light scattering smoke alarm; a photocell and a light 


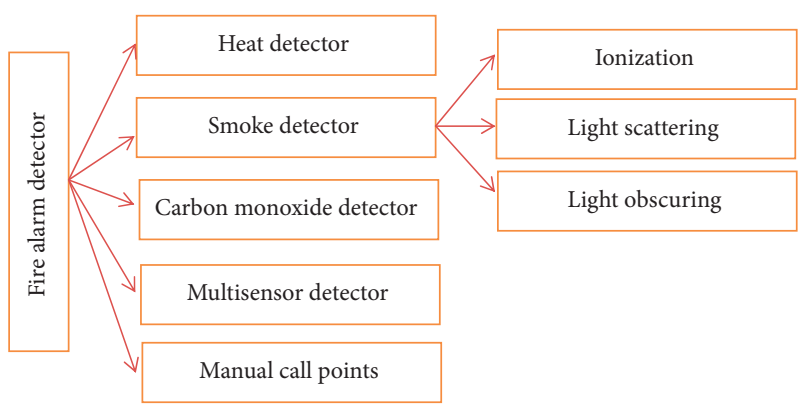

FIgURE 1: Fire alarm detectors.

source are segregated by a darker chamber so that the light source does not fall on the photocell. The passing of smoke into the chamber scatters the light from the origin, which falls on the photocell. An alert system is being triggered by the photocell output.

(iii) Light Obscuring. Smoke interferes with such a light beam between a light source and a photocell in the Light obscuring fire alarm. The photocell detects the amount of light that strikes it. A variance in photocell output is being used to trigger an alarm. With the light source and photocell placed some distance away, this sort of fire detection system can be used to protect huge regions [23].

2.1.3. Carbon Monoxide Detectors. Carbon monoxide detection systems, also recognized as CO smoke detectors, are digital sensors that detect the presence of carbon monoxide in the air and alert the user to the presence of a fire. Carbon monoxide is a highly toxic gas that is produced during the combustion process. These sensors are not the same as carbon monoxide detectors, which are used in homes to safeguard citizens from carbon monoxide generated by incomplete combustion in equipment such as gas fires or boilers. Carbon monoxide flame detectors use the same type of sensor as household sensors, but they are more sensitive and respond faster.

2.1.4. Multisensor Detectors. Multisensor detectors merge optical and temperature sensor inputs and procedure those using a sophisticated algorithm constructed into the detector circuit board. When the sensor is polled by the control panel, it returns a value determined by the combined responses of the optical and heat sensors. They are intended to be resistant to a wide range of burning.

2.1.5. Manual Call Points. A Manual Call Point, also known as a Break Glass Call Point, is a device that allows staff to sound the alarm by breaking the frangible component on the fascia, triggering the alarm.

2.2. DMS-2017B Machinery Operation Simulator. A simulator is an operable device developed by computer software for simulation and training, which is often used to replace real disasters and accident experiments to avoid personal injury [24]. The experimental environment is volatile due to the flow of persons and changes in ship sailing conditions, resulting in great deviation of environmental impact factors during each experiment. DMS-2017B machinery operation simulator was tailored for this experiment in order to avoid these external factors from causing impact and personal injury DMS-2017B machinery operation simulator is shown in Figure 2; this simulator can simulate the operation of cabin facilities and different fire scenes using unity3D engine; an operator can simulate the behaviors of crew members or passengers in cabin from the first-person perspective [25]. Unity is a cross-platform game engine for creating video games and simulations for PCs, consoles, smart applications, and websites. It was first introduced just for OS X at Apple's Worldwide Developers Conference in 2005 and has been expanded to practically every accessible platform. It is developed by Unity Technologies. A threedimensional (3D) engine, often known as a game engine, is a system that allows virtual computer simulations to be created. A 3D engine contains various areas of operation that work together to create a digital world that is both immersive and realistic. A gaming engine's rendering element determines a scene's visual look, while the physics component decides how different objects should interact. Some engines additionally offer realism-enhancing tools like scripting and artificial intelligence. Moreover, the DMS-2017B machinery operation simulator program, which incorporates the theory of affordances, can assess the HMI function of shipboard alerts. A Human-Machine Interface (HMI) is a user interface or dashboard that links a person to a machine, system, or device and can be used to visually display data, track production time, trends, and tags and Monitor machine i/o in the industries of energy, oil, and gas, manufacturing, power, and transportation, etc. According to the Theory of Affordances, people see the environment not only in terms of object shapes and particular relationships but also in terms of object action possibilities (affordances) - seeing a thing implies seeing the action connected with it [26]. Under the framework of the Theory of Affordances, assume that the degree of affordance of an object is associated with the information it provides. The affordance of this object can be divided into the following four levels:

(1) Sensed (Sensory Affordance)

(2) Understood (Cognitive Affordance)

(3) Physically used (Physical Affordance)

(4) If it fulfills its intended goal (Functional Affordance) [27]

Illustrating the alarm system as an example, the alarm cannot be physically used by crew members or passengers, but it can hint persons to give proper responses. After steps are modified, the affordance of alarm features can be divided into the following five levels:

(1) The alarm is not noticed

(2) The alarm is noticed, but the hazard information to be transmitted is not understood 


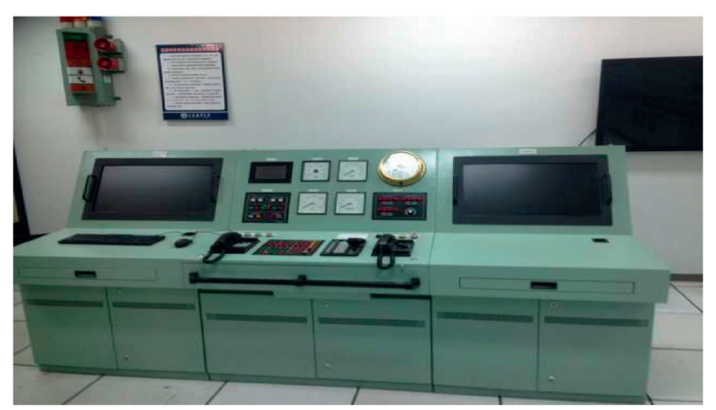

FIGURE 2: DMS-2017B machinery operation simulator.

(3) The information transmitted by the alarm is understood, but the action hinted by the alarm is not understood

(4) The action hinted by the alarm is understood, but the intended goal is not fulfilled

(5) Its intended goal is fulfilled

DMS-2017B machinery operation simulator is shown in Figure 2.

The simulator judged the feature design effect of the alarm by collecting the data about the behaviors and choices of subjects after the alarm sounded. The subject will receive a further questionnaire survey if the alarm has not yet fulfilled its intended goal within a given time after the alarm sounds. Those persons who failed to complete the questionnaire survey were deemed as invalid data and excluded from the statistical record.

According to theory of affordances, the degree of affordance of an object will level up. In this sense, the alarm should be noticed before understanding the hazard information transmitted by the alarm and knowing which action to be taken. Any data violating this level-up logic will be deemed as error data. Table 1 lists the judgment of data types.

The ordered logit model is a linear regression for dependent variables with an ordered value. The system is based on the response variable's accumulated probabilities: each cumulative probability's linear regression model is considered to be a linear function of the variables, with Regression Coefficients constant across Response Categories [28]. The collected data were analyzed using the ordered logit model. Assume that $N$ persons are affected by a thing, $i=1,2,3 \ldots, N$, and one of them, $\mathrm{i}$, the level of affordance $Y_{i}$ he gained is subject to the HMI impact, then $Y_{i}$ can be only decided by the latent variable of the thing, $D_{i}$. According to the ordered logit model, the latent variable $D_{i}$ can be written as follows [29]:

$$
D i=\sum_{K=0}^{K}\left(B_{k} X_{i k}+\varepsilon_{i}\right)=Z_{i}+\varepsilon_{i} .
$$

The latent variable $D_{i}$ is equal to a linear function decided by $K$ factors of the thing, $k=1,2,3 \ldots, K, X_{i k}$ refers to the value of the $\mathrm{k}_{\mathrm{th}}$ factor of the thing, $\beta_{k}$ refers to the correlation coefficient of the $\mathrm{k}_{\mathrm{th}}$ factor of the thing. The error term $\varepsilon_{i}$ in the above equation deals with inaccurate measurement or any factor not included. When $\beta_{k}>0$, the $k_{\text {th }}$ factor of the thing is considered to be greater and the degree of affordance of this thing increases. When $\beta_{k}<0$, the $k_{\text {th }}$ factor of the thing is considered to be smaller and the degree of affordance of this thing also increases. Take the ship alarm system as an example. Its alarm volume, whether auxiliary language broadcast is used, and the display mode of signs can be considered as relevant factors of the alarm.

$Y_{i}$ is based on the latent variable $D_{\mathrm{i}}$ and the threshold value $\left(\delta_{1}, \delta_{2}, \delta_{3} \ldots, \delta_{n}\right)$, as shown as follows:

$$
\begin{aligned}
& Y_{i}+0, \quad \text { if } D_{i}<\delta_{1}, \\
& Y_{i}=1, \quad \text { if } \delta_{1} \leq D_{i}<\delta_{2}, \\
& Y_{i}=n-1, \quad \text { if } \delta_{n-1} \leq D_{i}<\delta_{n}, \\
& Y_{i}=n, \quad \text { if } \delta_{n} \leq D_{i} .
\end{aligned}
$$

Take the alarm system as an example, the affordance of the alarm is divided into five levels; the level of affordance other than external factors depends on whether the latent variable $D i$ has spanned over a threshold value then the probability of $Y_{i}=0,1,2,3,4$ can be written as follows [30]:

$$
\begin{aligned}
& P\left(Y_{i}=0\right)=P\left(Z_{i}+\varepsilon_{i}<\delta_{1}\right)=F\left(\delta_{1}-Z_{i}\right), \\
& P\left(Y_{i}=1\right)=P\left(\delta_{1} \leq Z_{i}+\varepsilon_{i}<\delta_{2}\right)=F\left(\delta_{2}-Z_{i}\right)-\left(\delta_{1}-Z_{i}\right), \\
& P\left(Y_{i}=2\right)=P\left(\delta_{2} \leq Z_{i}+\varepsilon_{i}<\delta_{3}\right)=F\left(\delta_{3}-Z_{i}\right)-\left(\delta_{2}-Z_{i}\right), \\
& P\left(Y_{i}=3\right)=P\left(\delta_{3} \leq Z_{i}+\varepsilon_{i}<\delta_{4}\right)=F\left(\delta_{4}-Z_{i}\right)-\left(\delta_{3}-Z_{i}\right), \\
& P\left(Y_{i}=4\right)=P\left(\delta_{4} \leq Z_{i}+\varepsilon_{i}\right)=P\left(\delta_{4}-Z_{i} \leq \varepsilon_{i}\right) .
\end{aligned}
$$

$F(x)=P\left(\varepsilon_{i}<x\right)$ is the cumulative probability distribution function of the error term. If the ordered logit model is used, assume that $F()$ conforms to the logical distribution. The unknown parameters included in equations (1) and (3) are assessed by defining a likelihood function, the perceived degree of $k_{\text {th }}$ factor on latent variable $D_{i}$ is judged from $\beta_{k}$ and $P$.

\section{Experiment}

This segment of the paper denotes the experiments performed and the simulation results of the DMS-2017B machinery operation simulator carried out through those experiments. Multiple simulation experiments were conducted on the DMS-2017B machinery operation simulator. Among the experiments and simulation results, the top two, such as cabin experiment and binomial testing experiment, are discussed here. By comparing the experimental results, we can better compare the differences between different experimental methods. All the experiments have been performed on a Laptop computer (Intel Core-i7, 7th generation, having a processor of $2.7 \mathrm{GHz}, 32 \mathrm{GD}$ RAM, and Windows 10 operating system).

3.1. Participants. The function of a ship fire alarm is to summon the crew to the fire station. In this sense, a ship fire alarm should be intended for the ship's crew. So the 
TABLE 1: Affordance level judgment table.

\begin{tabular}{|c|c|c|c|c|c|}
\hline $\begin{array}{l}\text { If the intended goal is } \\
\text { fulfilled after setting off }\end{array}$ & $\begin{array}{c}\text { If no choice is made } \\
\text { for there is any } \\
\text { problem }\end{array}$ & $\begin{array}{c}\text { If the alarm is } \\
\text { noticed }\end{array}$ & $\begin{array}{l}\text { If the information transmitted } \\
\text { by the alarm is understood }\end{array}$ & $\begin{array}{l}\text { If the action hinted by } \\
\text { the alarm is understood }\end{array}$ & $\begin{array}{l}\text { Level of } \\
\text { affordance }\end{array}$ \\
\hline $\bar{Y}$ & Null & Null & Null & Null & 4 \\
\hline $\mathrm{N}$ & $\mathrm{Y}$ & Random & Random & Random & Invalid data \\
\hline $\mathrm{N}$ & $\mathrm{N}$ & $\mathrm{N}$ & $\mathrm{N}$ & $\mathrm{N}$ & 0 \\
\hline $\mathrm{N}$ & $\mathrm{N}$ & $\mathrm{N}$ & $\mathrm{Y}$ & Random & Error data \\
\hline $\mathrm{N}$ & $\mathrm{N}$ & $\mathrm{N}$ & Random & $\mathrm{Y}$ & Error data \\
\hline $\mathrm{N}$ & $\mathrm{N}$ & $\mathrm{Y}$ & $\mathrm{N}$ & $\mathrm{N}$ & 1 \\
\hline $\mathrm{N}$ & $\mathrm{N}$ & $\mathrm{Y}$ & $\mathrm{N}$ & $\mathrm{Y}$ & Error data \\
\hline $\mathrm{N}$ & $\mathrm{N}$ & $\mathrm{Y}$ & $\mathrm{Y}$ & $\mathrm{N}$ & 2 \\
\hline $\mathrm{N}$ & $\mathrm{N}$ & $\mathrm{Y}$ & $\mathrm{Y}$ & $\mathrm{Y}$ & 3 \\
\hline
\end{tabular}

experimental participants were mainly students majoring in navigation and marine engineering. Participants are the students as holders of certificates of professional training for seafarers, passed the CCS English test for general seafarers, and can proficiently operate the DMS-2017B machinery operation simulator. Considering the eligibility for marine navigation, all participants are of the male gender, without color blindness and hearing impairment. 618 participants were chosen for this experiment, age group from 20 to 29, with an average age of 22 years old. Career experience and nationality were not observed as a part of this experiment and will be discussed in subsequent works.

To avoid the influence of previous experimental experience, the cabin experiment was classified into 6 groups, 25 different participants in a group, and the simulator-based experiment was classified into 6 groups, 48 different participants in a group. There are five groups of experiments in binomial testing. 36 different participants were assigned to each group.

3.2. Subjects. We have considered the feature design of the ship fire alarm here. Because a ship fire alarm has an auditory and visual function, the auditory and visual design of the fire alarm must accord with the IMO regulations applicable to shipboard alerts. According to the international maritime organization (IMO), ship fire alarms use a continuous alarm or a pulse alarm with a frequency ranging from $0.5 \mathrm{~Hz}$ to $2.0 \mathrm{~Hz}$. Therefore, the waveforms used in the experiment are two kinds of commonly used continuous alarm or $1 \mathrm{~Hz}$ square wave alarm with high and low staggered signal frequencies. Previous works on alarm sound revealed that the alarm sound complemented with broadcast could improve the alarm effect. As a result, "Fire alarm, please go to the fire station," recorded broadcasting in Chinese and English languages, was added to the alarm sound as a new design type. Conventions and regulations only set out the minimum limits on the alarm sound pressure. For instance, LSA Code specifies that the upper limit of alarm sound pressure should not exceed $120 \mathrm{~dB}$, and the ship alarm is generally designed above $60 \mathrm{~dB}$ with a minimum interval of $15 \mathrm{~dB}$. Previous experiments on fire alarm sound pressure have affirmed that $90 \mathrm{~dB}$ can effectively wake up those who fall asleep. Therefore, we carried out works in the case of $60 \mathrm{~dB}, 75 \mathrm{~dB}$, and $90 \mathrm{~dB}$. For the fire alarm symbol, the IMO only specified the symbol with red color instead of specifying that the symbols should be static or dynamic. The static symbol is considered as the regular design. We added dynamic symbols at a flashing frequency of $1 \mathrm{~Hz}$ as a new design type. Feature combination design number reference of ship fire alarm is presented in Table 2.

Given the combination of different features (sound pressure, waveform, symbol type, broadcast type), there are 24 different designs as given in Table 2. 6 designs as mentioned below were examined to traverse the affordance of fire alarm feature design: DN1 is a static symbol, $60 \mathrm{~dB}$, continuous alarm, no broadcasting; DN9 is a static symbol, $75 \mathrm{~dB}$, continuous alarm, no broadcasting; DN10 is a static symbol, $75 \mathrm{~d}$, continuous alarm, broadcast with Chinese and English recording; DN11 is a dynamic symbol, $75 \mathrm{~dB}$, continuous alarm, no broadcasting; DN13 is static symbol, $75 \mathrm{~dB}, 1.0 \mathrm{~Hz}$ pulse alarm, no broadcasting; DN17 is a static symbol, $90 \mathrm{~dB}$, continuous alarm, no broadcasting.

3.3. Simulator Experiment with DMS-2017B Machinery Operation Simulator. Figure 3, shows the scene constructed by the DMS-2017B machinery operation simulator according to the real objects in the cabin experiment. Figure 3(a) simulates the fire scene in the auxiliary engine room. Figure 3(b) shows the appearance image of DN1, DN9, DN10, DN13, and DN17. Figure 3(c) shows the appearance image of DN 11. At the beginning of the experiment, we told the participants to have operation training in the central control room. The participants appeared in the central control room as an intern and began the training from the first perspective. External speaker of the DMS-2017B machinery operation simulator will continue to make noise recorded in the cabin experiment to simulate the real cabin environment.

The top view of the cabin structure is shown in Figure 4. Similar to the installation position of the fire alarm in the cabin experiment, the fire alarm is installed near the door of the central control room in the simulator experiment. The walking time from the entrance of the central control room to the fire station is 56 seconds by using the path finding function of the simulator? The experiment was called to end in five minutes after the alarm was triggered, and the experimental data were collected for the statistical record. Any participant returning to the fire station by simulator control 
TABLE 2: Feature combination design number reference of the ship fire alarm.

\begin{tabular}{|c|c|c|c|c|}
\hline Fire alarm design number & Sound pressure $(\mathrm{dB})$ & Waveform & Symbol type & Broadcast type \\
\hline DN1 & \multirow[t]{8}{*}{60} & Continuous alarm & Static symbol & No broadcasting \\
\hline DN2 & & \multirow{7}{*}{$1.0 \mathrm{~Hz}$ pulse alarm } & & Broadcast with Chinese and English recording \\
\hline DN3 & & & Flashing symbol & No broadcasting \\
\hline DN4 & & & & Broadcast with Chinese and English recording \\
\hline DN5 & & & Static symbol & No broadcasting \\
\hline DN6 & & & & Broadcast with Chinese and English recording \\
\hline DN7 & & & Flashing symbol & No broadcasting \\
\hline DN8 & & & & Broadcast with Chinese and English recording \\
\hline DN9 & \multirow[t]{8}{*}{75} & Continuous alarm & Static symbol & No broadcasting \\
\hline DN10 & & \multirow{7}{*}{$1.0 \mathrm{~Hz}$ pulse alarm } & & Broadcast with Chinese and English recording \\
\hline DN11 & & & Flashing symbol & No broadcasting \\
\hline DN12 & & & & Broadcast with Chinese and English recording \\
\hline DN13 & & & Static symbol & No broadcasting \\
\hline DN14 & & & & Broadcast with Chinese and English recording \\
\hline DN15 & & & Flashing symbol & No broadcasting \\
\hline DN16 & & & & Broadcast with Chinese and English recording \\
\hline DN17 & \multirow[t]{8}{*}{90} & Continuous alarm & Static symbol & No broadcasting \\
\hline DN18 & & \multirow{7}{*}{$1.0 \mathrm{~Hz}$ pulse alarm } & & Broadcast with Chinese and English recording \\
\hline DN19 & & & Flashing symbol & No broadcasting \\
\hline DN20 & & & & Broadcast with Chinese and English recording \\
\hline DN21 & & & Static symbol & No broadcasting \\
\hline DN22 & & & & Broadcast with Chinese and English recording \\
\hline DN23 & & & Flashing symbol & No broadcasting \\
\hline DN24 & & & & Broadcast with Chinese and English recording \\
\hline
\end{tabular}

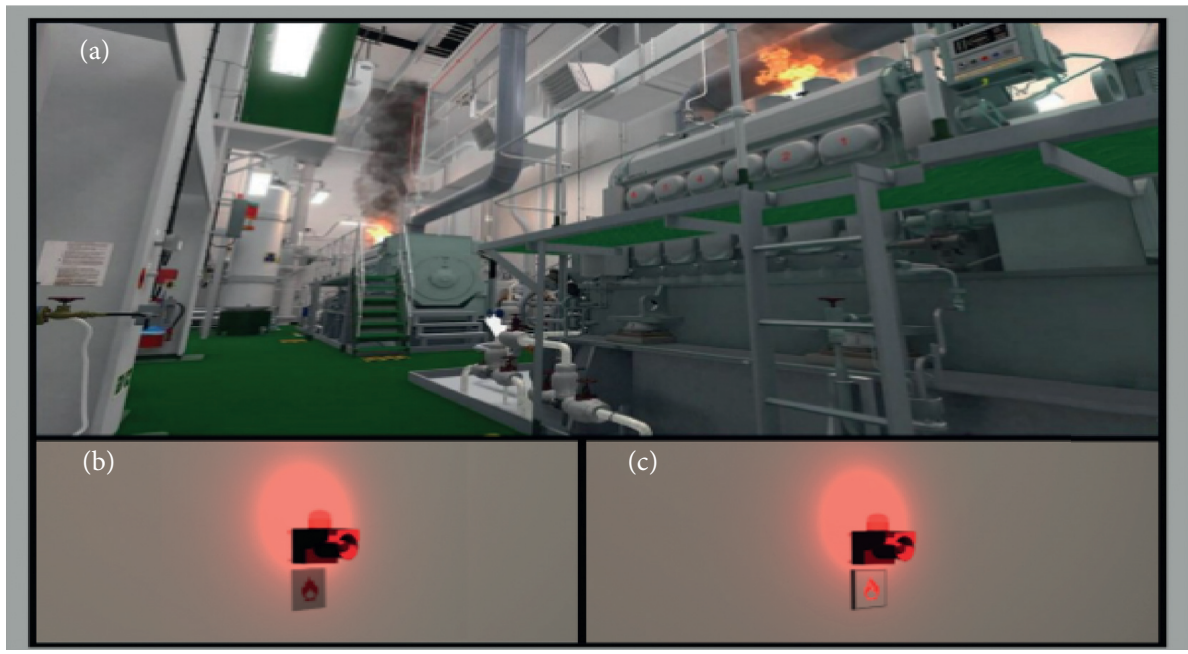

FIGURE 3: The scene constructed by DMS-2017B machinery operation simulator. (a) Fire scene in the auxiliary engine room. (b) Appearance feature of DN1, DN9, DN10, DN13, and DN17. (c) Appearance feature of DN11.

would be asked the question "did you arrive at the fire station because of the alarm," anyone with an affirmative response was considered to fulfill the intended goal, and anyone with a denied response was considered as invalid data. Any participant who failed to return to the fire station would be asked the question "if you want to return to the fire station, but failed to do so for operation," anyone with an affirmative response was considered to invalid data, and anyone with a denied response was further asked to answer three questions as presented in the following:

Question 1: did you notice the alarm?
Question 2: did the alarm let you obtain the information about a fire that has occurred?

Question 3: did the alarm let you obtain the reminder of gathering at the fire station?

The host collected all the experimental results of the simulators and judged the validity and affordance level of data against Table 1. For quantitative analysis, the experimental data were analyzed using the ordered logit model. The latent utility function which applies to the ship fire alarm system intended for this experiment can be written as follows: 


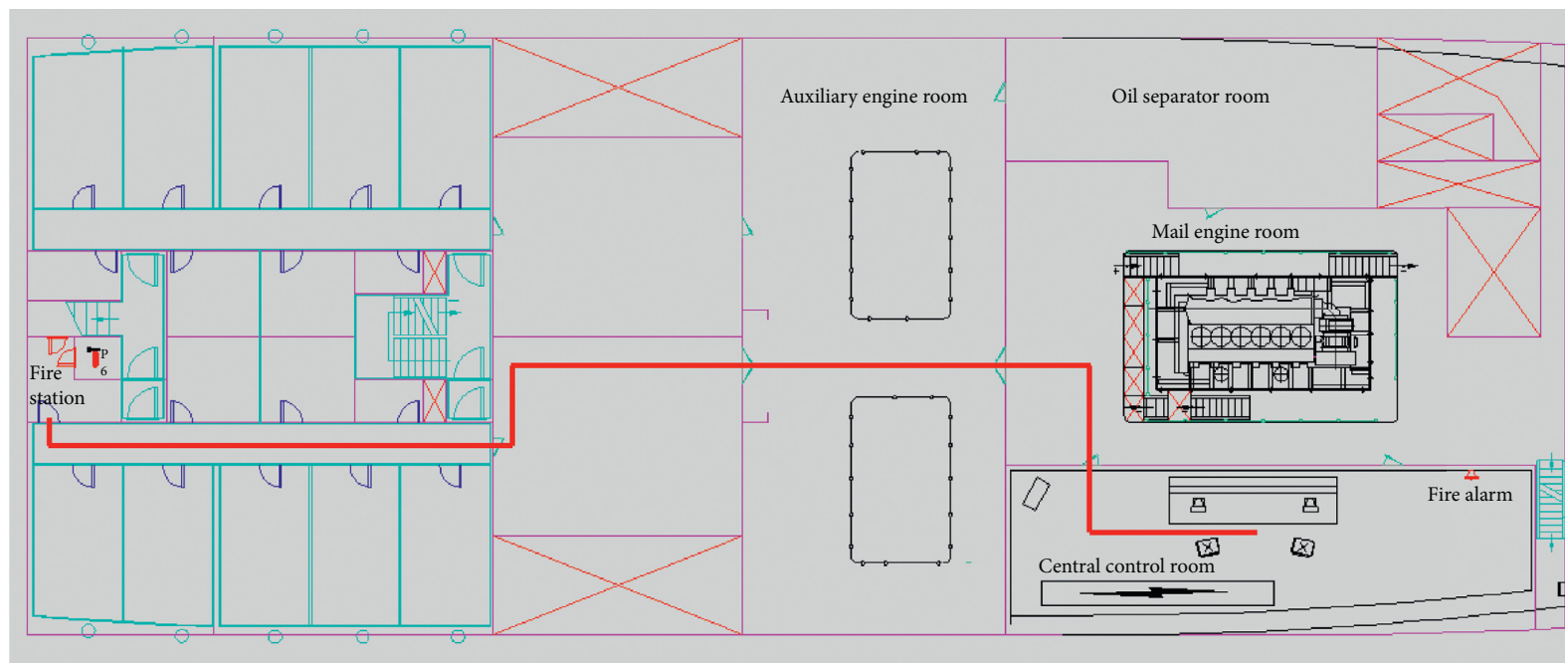

FIgURE 4: Top view of cabin structure in an experimental environment.

$$
D=s S+w W+f F+b B+\varepsilon .
$$

The latent variable $D$ is associated with the value of sound pressure $(S)$, waveform $(W)$, symbol type $(F)$, and broadcast type $(B)$, where $W, F$, and $B$ are the factors only with two values $(0,1), W=1$ if the waveform is pulse sound wave, $F=1$ if the symbol type is flashing symbol. Of broadcast type, $B=1$ if the original alarm is added with the recording broadcast. As $S$ has three values $(60 \mathrm{~dB}, 75 \mathrm{~dB}$, $90 \mathrm{~dB}$ ), it is generally treated as a covariate. To consider the auditory thresholds of sound pressure on alarm function, the first group consisting of $60 \mathrm{~dB}$ and $75 \mathrm{~dB}$ sound pressure data is analyzed by ordered logit model, and then the second group consisting of $75 \mathrm{~dB}$ and $90 \mathrm{~dB}$ sound pressure data is analyzed, and the value of $S$ with higher sound pressure in each group is 1 . Simulator experiment results of analysis based on ordered logit model are shown in Table 3.

The analysis results in Section 3.2 of 6 designs (such as DN1, DN9, DN10, DN11, DN13, and DN17) are given in Table 3. Assume that the test of parallel lines in the first group is given by the following:

$$
\begin{aligned}
& X_{60-75}^{2}=14.751, \\
& P_{60-75}=0.255>0.05 .
\end{aligned}
$$

While the test of parallel lines in the second group is denoted by the following:

$$
\begin{aligned}
& X_{75-90}^{2}=11.279, \\
& P_{75-90}=0.505>0.05 .
\end{aligned}
$$

From above, it is clear that the coefficient of the regression model is the same as the test of parallel lines has passed, and it was appropriate to use the ordered logit model in each test. Let us assume that model by fitting information of the first group is as follows:
TABLE 3: Simulator experiment results of analysis based on the ordered logit model.

Test of parallel lines: $X_{60-75}^{2}=14.751, P_{60-75}=0.255$

Model fitting information: $X_{60-75}^{2}=67.513, P_{60-75} \leq 0.001$

\begin{tabular}{lccc} 
Variable & Estimate & Wald & Significance \\
\hline$s_{60-75}$ & -1.088 & 7.815 & 0.005 \\
$w_{60-75}$ & -0.522 & 1.871 & 0.171 \\
$f_{60-75}$ & -0.964 & 6.359 & 0.012 \\
$b_{60-75}$ & -2.102 & 27.036 & 0.000 \\
\hline
\end{tabular}

Test of parallel lines: $X_{75-90}^{2}=11.279, P_{75-90}=0.505$

Model fitting information: $X_{75-90}^{2}=38.559, P_{75-90} \leq 0.001$

\begin{tabular}{lccc} 
Variable & Estimate & Wald & Significance \\
\hline$s_{75-90}$ & 0.089 & 0.056 & 0.814 \\
$w_{75-90}$ & -0.495 & 1.698 & 0.193 \\
$f_{75-90}$ & -0.930 & 5.983 & 0.014 \\
$b_{75-90}$ & -2.051 & 26.280 & 0.000 \\
\hline
\end{tabular}

$$
\begin{aligned}
& X_{60-75}^{2}=67.513, \\
& P_{60-75}=0.000<0.05 .
\end{aligned}
$$

While model fitting information of the second group is as follows:

$$
\begin{aligned}
X_{75-90}^{2} & =38.559, \\
P_{75-90} & =0.000<0.05 .
\end{aligned}
$$

Hence, this indicates that the analysis results have statistical significance, and the results derived should be valid.

The Bonferroni correction is a multiple-comparison correction that is employed when doing several dependent or independent statistical tests at the same time. So to correct the statistical errors of multiple hypothesis tests on a data set, we use Bonferroni correction. The experiment was carried out to check the significance within $95 \%$ confidence interval. 
Significance should be less than $0.5 / n$, where $n$ is the number of tests, two tests for $60 \mathrm{~dB}$ and $75 \mathrm{~dB}, 75 \mathrm{~dB}$ and $90 \mathrm{~dB}$ were carried out here. The null hypothesis is rejected only if the significance is less than 0.025 . In this case, $s_{60-75} f_{60-75} b_{60-75}$ $f_{75-90}$ and $b_{75-90}$ can observe statistically significant differences. It was considered that in our proposed cabin environment, sound pressure increased from $60 \mathrm{~dB}$ to $75 \mathrm{~dB}$; symbol type and if recording broadcasting is added would have a significant impact on the function of ship fire alarm, but the impact of sound pressure increased from $75 \mathrm{~dB}$ to $90 \mathrm{~dB}$; the waveform of alarm sound on its function is negligible.

3.4. Cabin Experiment. We use practice teaching at sea for cabin experiments. As shown in Figure 4, the top view of the cabin structure where the experiment is located is shown. The participant was trained in the central control room alone, and the fire alarm for testing was installed in the fixed position of the central control room. The normal walking time from the central control room to the fire station is about 1 minute. The experiment was called to end in five minutes after the time alarm triggered, and the experimental data were collected for the statistical record. Any participant who failed to return to the fire station would be asked the question, "if you want to return to the fire station but failed to do so for the difficulty of path finding," anyone with an affirmative response was considered to invalid data, and anyone with a denied response was further asked to answer the same three questions in Section 3.3 as in the simulator experiment. The work flow cabin experiment is shown in Figure 5.

Figure 5 shows work flow of proposed Cabin experiment, which starts from the trained participants by asking questions of Section 3.2. If any participant failed to answer the question in a minute, then he will begin the experiment. If the participant denies the response to a question, then another question will be asked from the questions mentioned in Section 3.2. After completing 5 minutes, the experiment is completed by generating the desired result.

For this experiment, we use formula (4) as the latent utility function, where the values and definitions of variables $S, W, F$, and $B$ are the same as those in the simulator experiment and the data with a sound pressure of $60 \mathrm{~dB}$ and $75 \mathrm{~dB}$ constitute a group, and the data with a sound pressure of $75 \mathrm{~dB}$ and $90 \mathrm{~dB}$ form another group. We used an ordered logit model to analyze the two groups of data, and the analysis results are as in Table 4 .

From the test of parallel lines and model fitting information in Table 4, we can see that it was appropriate to use the ordered logic expression in the two tests, and the results derived should be valid. The $p$ value corrected by the Bonferroni correction is 0.025 . By comparing the $p$ value and significance, it can be concluded that the impact of sound pressure increased from $60 \mathrm{~dB}$ to $75 \mathrm{~dB}$, symbol type and if recording broadcasting is added on the function of ship fire alarm is significant, and the impact of sound pressure increased from $75 \mathrm{~dB}$ to $90 \mathrm{~dB}$, the waveform of alarm sound on its function is negligible.
3.5. Binomial Testing Experiment. The binomial test is used when a test has two potential results (for example, success/ failure) and we have a thought regarding what the probability of accomplishment is. In simple words, a binomial test is used to determine whether observed test results differ from those predicted. Binomial testing is often used to assess the feature design of fire facilities. According to Section 3.2, DN9 is the most generic feature design for ship fire alarms under the IMO regulations. This is because it was designed with the static symbol, the sound pressure of $75 \mathrm{~dB}$, with no broadcasting, continuous, and it can be placed in a bridge or any environment other than bridge. We have obtained 5 pairs of Binomial testing by using the most generic subject as a reference in pairwise comparison and coupled the other five typical designs mentioned in Section 3.2 with DN9.

During our Binomial Testing experiment, all the participants were asked to sit behind the bench by facing the screen. A volume-controlled loudspeaker was placed in front of the bench by recording the noise. This recorded noise from the cabin is looped back with the help of surrounding loudspeakers. After a pair of alarms was selected for the Binomial Testing experiment, the simulator screen captures of the scenes around two designs of fire alarms of the pairs were displayed on the left and right screen. Each participant can operate the left or right button on the bench to select the fire alarm sound on which screen will be played back and be asked to voluntarily select the options in the questionnaire. The questionnaire explicitly indicated that any or even all options may be unselected if it is impossible to identify strengths and weaknesses. Questions included in the questionnaire include the following:

Q1: which fire alarm detail design is easier to notice? Q2: which fire alarm detail design can transmit the fire information more easily?

Q3: which fire alarm feature design more clearly prompts the "gather at fire station" information?

Q4: which fire alarm feature design makes you feel that the current situation is extremely urgent and immediate measures are needed?

Q5: as a whole, which fire alarm design is more suitable to transmit and urge the crew to deal with the fire?

From the above questions, it is cleared that Question-1 studies the sensory affordance of alarms. Question-2 and Question-3 study the cognitive affordance of alarms. Question-4 studies the functional affordance of alarms. Question-5 is a general problem. Question-1 to Question-4 are used to figure out which step exactly worked. Statistics of binomial test results are shown in Table 5 .

As given in Table 5, 5 cycles of Binomial Testing were performed for pairwise comparison. After Bonferroni correction was used, The $p$ value corrected by the Bonferroni correction is 0.01 , and the null hypothesis can be rejected only when significance is less than 0.1 . From a statistical point of view, replacing static symbols with flashing symbols had a significant impact on the function of a ship fire alarm by increasing sensory affordance and Functional Affordance. 


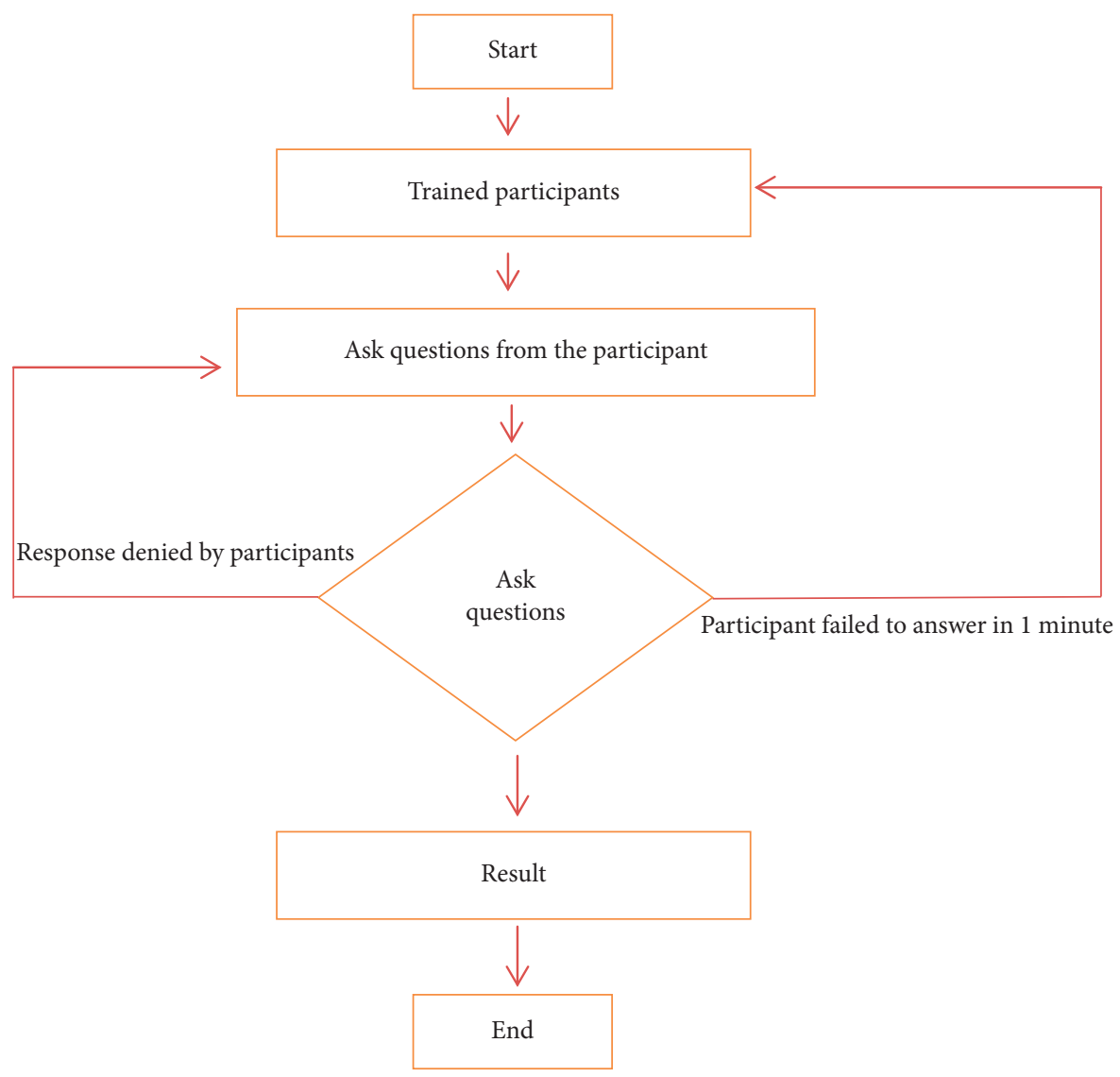

FIgURE 5: Flowchart of the cabin experiment.

TABLE 4: Cabin experiment results of analysis based on the ordered logit model.

\begin{tabular}{lccc}
\hline \multicolumn{5}{c}{ Test of parallel lines: $X_{60-75}^{2}=13.871, P_{60-75}=0.309$} \\
Model fitting information: $X_{60-75}^{2}=47.266, P_{60-75} \leq 0.001$ \\
Variable & Estimate & Wald & Significance \\
\hline$s_{60-75}$ & -1.383 & 6.200 & 0.013 \\
$w_{60-75}$ & -0.802 & 2.206 & 0.138 \\
$f_{60-75}$ & -1.373 & 6.514 & 0.011 \\
$v_{60-75}$ & -2.249 & 16.135 & 0.000 \\
\hline \multicolumn{4}{c}{ Test of parallel lines: $X_{75-90}^{2}=9.170, P_{75-90}=0.688$} \\
\multicolumn{1}{c}{ Model fitting information: $X_{75-90}^{2}=23.727, P_{75-90} \leq 0.001$} \\
Variable & Estimate & Wald & Significance \\
\hline$s_{75-90}$ & 0.053 & 0.010 & 0.919 \\
$w_{75-90}$ & -0.734 & 1.894 & 0.169 \\
$f_{75-90}$ & -1.293 & 5.937 & 0.015 \\
$v_{75-90}$ & -2.160 & 15.372 & 0.000 \\
\hline
\end{tabular}

Sound pressure increased from $60 \mathrm{~dB}$ to $90 \mathrm{~dB}$ enhances the sensory affordance of the alarm to capture attention. Recorded broadcasting enhances the function of the fire alarm by increasing sensory affordance, Cognitive Affordance, and Functional Affordance. After the continuous alarm was changed to a $1 \mathrm{~Hz}$ pulse alarm, the significance of Question-4 is 0.008 . The change of the waveform of alarm was considered to have a significant impact on the Functional Affordance of the fire alarm. However, the significance of Question-5 is 0.065 , which merely indicates that change of waveform enhanced the general function of a fire alarm to a certain extent, but it was not considered as statistically significant.

In this part, we clarify the general status of the proposed scheme for ship fire alarm system, as we realize that the general status is quite possibly the most instructive boundaries in the results of the tests as it is anything but an overall image of the state of the ship alarm system, including three situations, such as normal, caution, and alarm; thus, Figure 6 shows the comparison of the proposed ship fire alarm system (from 2015 to 2020) for normal, caution, and alarm. Where the Normal status shows the test is inside the commonplace qualities, while caution and alarm could demonstrate that the threshold values (for first gathering $60 \mathrm{~dB}$ and $75 \mathrm{~dB}$ sound pressing factor information and for second gathering $75 \mathrm{~dB}$ and $90 \mathrm{~dB}$ sound pressing factor information) exceeded, or that the sample taken was not considerable, among different reasons; hence, further examination is needed from the ship alarm system staff as a potential issue could emerge from these situations.

\section{Discussion}

This paper presents a method to assess the fire alarm features by using the machinery operation simulator and theory of affordances. The same subjects were involved in the 
TABle 5: Statistics of binomial test results.

\begin{tabular}{|c|c|c|c|c|c|c|c|c|c|c|c|c|c|c|c|}
\hline \multirow{2}{*}{ Category } & \multicolumn{3}{|c|}{ Question-1 } & \multicolumn{3}{|c|}{ Question-2 } & \multicolumn{3}{|c|}{ Question-3 } & \multicolumn{3}{|c|}{ Question-4 } & \multicolumn{3}{|c|}{ Question-5 } \\
\hline & $N$ & $C$ & $S$ & $N$ & C & $S$ & $N$ & C & $S$ & $N$ & C & $S$ & $N$ & C & $S$ \\
\hline Test1 & & & & & & & & & & & & & & & \\
\hline DL1 & 0 & 0 & 0.000 & 0 & Null & Null & 0 & Null & Null & 0 & Null & Null & 0 & 0 & 0.000 \\
\hline DL9 & 33 & 100 & & 0 & Null & & 0 & Null & & 0 & Null & & 33 & 100 & \\
\hline Test2 & & & & & & & & & & & & & & & \\
\hline DL9 & 0 & 0 & 0.000 & 0 & 0 & 0.000 & 0 & 0 & 0.000 & 0 & 0 & 0.000 & 0 & 0 & 0.000 \\
\hline DL10 & 26 & 100 & & 31 & 100 & & 31 & 100 & & 24 & 100 & & 36 & 100 & \\
\hline Test3 & & & & & & & & & & & & & & & \\
\hline DL9 & 0 & 0 & 0.000 & 0 & 0 & 0.125 & 0 & 0 & 0.500 & 0 & 0 & 0.002 & 0 & 0 & 0.000 \\
\hline DL11 & 29 & 100 & & 4 & 100 & & 2 & 100 & & 10 & 100 & & 32 & 100 & \\
\hline Test4 & & & & & & & & & & & & & & & \\
\hline DL9 & 2 & 22 & 0.180 & 0 & 0 & Null & 0 & Null & Null & 0 & 0 & 0.008 & 2 & 18 & 0.065 \\
\hline DL13 & 7 & 78 & & 1 & 100 & & 0 & Null & & 8 & 100 & & 9 & 82 & \\
\hline Test5 & & & & & & & & & & & & & & & \\
\hline DL9 & 0 & 0 & 0.000 & 0 & Null & Null & 0 & Null & Null & 0 & 0 & Null & 0 & 0 & 0.000 \\
\hline DL17 & 35 & 100 & & 0 & Null & & 0 & Null & & 1 & 100 & & 35 & 100 & \\
\hline
\end{tabular}

$N=$ number of options, $C=$ percentage of options, and $S=$ significance.

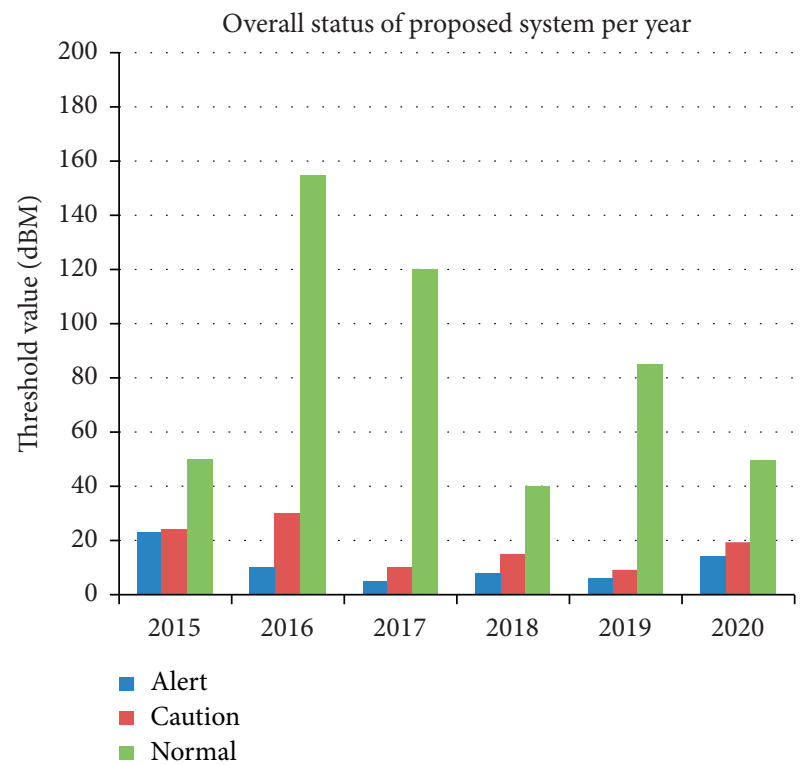

FIGURE 6: Overall performance from 2015 to 2020.

experiment process using cabin experiment and conventional Binomial Testing. It was found that the results obtained from the simulator experiment and that from the cabin experiment are in substantial agreement, but the results obtained from Binomial Testing are slightly different from those from the simulator experiment and the cabin experiment.

The results of three experiments indicated that the sound pressure increased from $60 \mathrm{~dB}$ to $75 \mathrm{~dB}$ and replacing static signs with dynamic signs can significantly enhance the function of fire alarm under the noise environment in a cabin, which agrees with the conclusion drawn in the study of dissuasive exit signage. The addition of recorded broadcasting also significantly improves the affordances of the ship fire alarm. Previous works reported that the evacuation effect of adding broadcasting is better due to higher reliability.
For fire alarm waveform, it is allowed to use a continuous alarm or $0.5 \mathrm{~Hz}-2.0 \mathrm{~Hz}$ pulse alarm in Resolution A.1021 (26). In this regard, the alarm sound from continuous alarm to $1 \mathrm{~Hz}$ square wave alarm was compared through three experiments. The significance value of the impact of a waveform on the function of a ship fire alarm is small (0.065 0.193), but this only means that a pulsing alarm can further enhance the function of a fire alarm compared with a continuous alarm. Since the null hypothesis cannot be rejected, we cannot statistically identify the significant effect of replacing continuous alarm with pulse alarm. Therefore, it is feasible to use the sound modes of ship fire alarm under two regulations as stated above.

According to the statistical results concerning the sound, pressure increased from $75 \mathrm{~dB}$ to $90 \mathrm{~dB}$; the significance of the simulator experiment and the cabin experiment is much higher than the pvalue. According to the results of Binomial Testing, the null hypothesis is rejected and it is considered as a significant impact factor, which can be attributed to the difference between the three experiment procedures. The simulator experiment and cabin experiment are intended to experiment with or rate the design of a single fire alarm, while Binomial Testing is intended to compare the strengths and weaknesses as to the design of two fire alarms under a scene, so we took it for granted that a design with intense senses (e.g., high volume and brightness) should be better, but the impact of alarm sound pressure on fire alarm has an auditory threshold. Relevant research on fire alarms suggests that a volume change under the auditory threshold has a significant impact on alarm function, but a change beyond the auditory threshold has a slight impact on alarm function.

The comparison of results affirmed that it is feasible to assess the function of the fire alarm through the simulator experiment. However, some deficiencies were still found during the experiment. Firstly, all experiments were carried out under the same noise environment, without considering a quiet environment. Because the ship fire alarm was the intended object of this experiment, it is usually installed in a 
relatively noisy working environment. Secondly, participants were screened by a fixed standard: male interns who passed the CCS English test for general seafarers and obtained certificates of professional training for seafarers, with normal vision and auditory ability. This makes the difference between participants in each group of experiments very small, which is conducive to shielding the impact of interference factor on the results of qualitative analysis. The impact of noise environment and individual differences will be further discussed in subsequent works.

\section{Conclusions}

In this paper, the DMS-2017B machinery operation simulator coupled with the theory of affordances was proposed as a method to assess the design feature of a ship fire alarm. Compared with the cabin experiment, the simulator experiment can unify the noise environment to avoid the influence of environmental differences on the experimental results. In addition, the simulator experiment can also simulate the disaster scene in the real experiment to avoid personal injury of the participants. To assess all sorts of alarms installed on marine vehicles and the feature design of navigation, machine control, and other devices that transmit information by the auditory and visual function, we have used the HMI function. Furthermore, the HMI experiment is carried out on land fire as well as on fire-extinguishing facilities. A well-designed ship fire alarm can improve the efficiency of handling accidents and evacuation and, in turn, increase the survival rate. The method proposed in this study will be the starting point for assessing the feature design of the alarm, and the experimental data will be referenced for the design of the ship fire alarm. For the future, we have planned to design an intelligent ship alarm system with wireless capability. In addition, we have planned to address the issues and attacks related to the ship fire alarm system along with explaining new techniques that enhance the efficiency of the ship fire alarm system.

\section{Data Availability}

The data used to support the findings of this study are available from the corresponding author upon request.

\section{Conflicts of Interest}

The authors declare no conflicts of interest.

\section{Acknowledgments}

This work was supported by the National Natural Science Foundation of China (51479017).

\section{References}

[1] W. Zhang, X. Feng, F. Goerlandt, and Q. Liu, "Towards a convolutional neural network model for classifying regional ship collision risk levels for waterway risk analysis," Reliability Engineering \& System Safety, vol. 204, Article ID 107127, 2020.
[2] L. Du, O. Valdez Banda, F. Goerlandt, Y. Huang, and P. Kujala, "A COLREG-compliant ship collision alert system for stand-on vessels," Ocean Engineering, vol. 218, no. 3, Article ID 107866, 2020.

[3] D. Chen, Y. Pei, and Q. Xia, "Research on human factors cause chain of ship accidents based on multidimensional association rules," Ocean Engineering, vol. 218, Article ID 107717, 2020.

[4] M. Baldauf, S. Fischer, R. Mehdi, and M. Gluch, "A perfect warning to avoid collisions at sea?" Sci J Marit Univ Szczecin, vol. 49, no. 121, pp. 53-64, 2017.

[5] E. Eliopoulou, A. Papanikolaou, and M. Voulgarellis, "Statistical analysis of ship accidents and review of safety level," Safety Science, vol. 85, pp. 282-292, 2016.

[6] Y. Huang and P. H. A. J. M. van Gelder, "Time-varying risk measurement for ship collision prevention," Risk Analysis, vol. 40, no. 1, pp. 24-42, 2020.

[7] M. Gil, K. Wróbel, J. Montewka, and F. Goerlandt, "A bibliometric analysis and systematic review of shipboard decision support systems for accident prevention," Safety Science, vol. 128, Article ID 104717, 2020.

[8] F. Goerlandt, H. Goite, O. A. Valdez Banda, A. Höglund, P. Ahonen-Rainio, and M. Lensu, "An analysis of wintertime navigational accidents in the northern baltic sea," Safety Science, vol. 92, pp. 66-84, 2017.

[9] E. Akyuz, "A marine accident analysing model to evaluate potential operational causes in cargo ships," Safety Science, vol. 92, pp. 17-25, 2017.

[10] S. E. Roberts, P. B. Marlow, and B. Jaremin, "Shipping casualties and loss of life in UK merchant shipping, UK second register and foreign flags used by UK shipping companies," Marine Policy, vol. 36, no. 3, pp. 703-712, 2012.

[11] H. Kim, S. Haugen, and I. B. Utne, "Assessment of accident theories for major accidents focusing on the MV SEWOL disaster: similarities, differences, and discussion for a combined approach," Safety Science, vol. 82, pp. 410-420, 2016.

[12] H. Kim, M.-I. Roh, and S. Han, "Passenger evacuation simulation considering the heeling angle change during sinking," International Journal of Naval Architecture and Ocean Engineering, vol. 11, no. 1, pp. 329-343, 2019.

[13] U.S. Fire Administration, Residential Building FiresInternational Cultural Publishing Company, Beijing, China, 2014.

[14] M. Ahrens, "Smoke alarm presence and performance in U.S. home fires," Fire Technology, vol. 47, no. 3, pp. 699-720, 2011.

[15] H. Liu, S. Li, L. Gao, and T. Wu, "About automatic fire alarm systems research," in 2010 2nd IEEE International Conference on Information Management and Engineering, pp. 419-421, Chengdu, China, April 2010.

[16] G. Martin, H. Boehmer, and S. M. Olenick, "Thermally-induced failure of smoke alarms," Fire Technology, vol. 56, no. 2, pp. 673-692, 2020.

[17] K. A. M. Moinuddin, D. Bruck, and L. Shi, “An experimental study on timely activation of smoke alarms and their effective notification in typical residential buildings," Fire Safety Journal, vol. 93, pp. 1-11, 2017.

[18] D. Bruck, "The who, what, where and why of waking to fire alarms: a review," Fire Safety Journal, vol. 36, no. 7, pp. 623-639, 2001.

[19] S. Ananthram, Z. Qing, and H. Yao-Win, Wireless Sensor Networks, Signal Processing and Communications Perspectives, John Wiley \& Sons Ltd, the Atrium, Southern Gate, Chichester, West Sussex PO19 8SQ, England, 2007.

[20] E. Ronchi, K. Fridolf, H. Frantzich, D. Nilsson, A. L. Walter, and H. Modig, "A tunnel evacuation experiment on 
movement speed and exit choice in smoke," Fire Safety Journal, vol. 97, pp. 126-136, 2018.

[21] J. Olander, E. Ronchi, R. Lovreglio, and D. Nilsson, "Dissuasive exit signage for building fire evacuation," Applied Ergonomics, vol. 59, pp. 84-93, 2017.

[22] E. Galea, H. Xie, and P. Lawrence, "Experimental and survey studies on the effectiveness of dynamic signage systems," Fire Safety Science, vol. 11, pp. 1129-1143, 2014.

[23] T. Stone, "Light pollution: a case study in framing an environmental problem," Ethics, Policy \& Environment, vol. 20, no. 3, pp. 279-293, 2017.

[24] H. Shen, J. Zhang, and H. Cao, "Marine engineering virtual training and evaluation system: a learning tool for marine engineers," International Journal of Engineering Education, vol. 32, no. 5, pp. 2083-2097, 2016.

[25] H. Shen, J. Zhang, H. Cao, and J. Feng, "Development research of marine engine room simulator for offshore supply vessel based on virtual reality technology," International Journal of Multimedia and Ubiquitous Engineering, vol. 11, no. 5, pp. 105-120, 2016.

[26] N. Masoudi, G. M. Fadel, C. C. Pagano, and M. V. Elena, "A review of affordances and affordance-based design to address usability," Proceedings of the Design Society: International Conference on Engineering Design, vol. 1, no. 1, pp. 1353-1362, 2019.

[27] R. Hartson, "Cognitive, physical, sensory, and functional affordances in interaction design," Behaviour \& Information Technology, vol. 22, no. 5, pp. 315-338, 2003.

[28] G. Baetschmann, K. E. Staub, and R. Winkelmann, "Consistent estimation of the fixed effects ordered logit model," Journal of the Royal Statistical Society: Series A, vol. 178, no. 3, pp. 685-703, 2014.

[29] L. Ruggiero, F. Achille, and d.O. Luigi, "A mixed logit model for predicting exit choice during building evacuations," Transportation Research Part A: Policy and Practice, vol. 92, pp. 59-75, 2016.

[30] X. Wang, Z. Liu, J. Wang, S. Loughney, Z. Zhao, and L. Cao, "Passengers' safety awareness and perception of wayfinding tools in a Ro-Ro passenger ship during an emergency evacuation," Safety Science, vol. 137, Article ID 105189, 2021.

[31] L. Xiong, M. Ball, and D. Bruck, "Comprarative investigation of "survival" and fatality factors in accidental residential fires," Fire Safety Journal, vol. 73, pp. 37-47, 2015. 